\title{
Validation of an Awareness and Preparedness on a Hearing Conservation Program Questionnaire: A Cross Sectional Study in Thailand
}

Kittisakdi Choomalee, B.Sc., Supeecha Rungruang, M.Sc., Chutarat Sathiraphanya, Ph.D., Thitiworn Choosong, Ph.D.

Research Unit of Holistic Health and Safety Management in Community, Department of Family Medicine and Preventive Medicine, Prince of Songkla University, Hat Yai, Songkhla 90110, Thailand.

Received 21 August 2017 • Accepted 8 January 2018 • Published online 24 May 2018

\section{Abstract:}

Objective: To validate a hearing conservation program (HCP) questionnaire based on the health belief model and stages of change model (or transtheoretical model).

Material and Methods: The perception levels of 145 workers who voluntarily participated at 2 companies were determined using this HCP questionnaire from April 2014 to September 2015. Exploratory factor analysis was performed to justify the final questionnaire.

Results: The final questionnaire had 24 items with 5 components: risk acceptance (8 items), perceived barriers (3 items), perceived benefits (5 items), role model (4 items), and the stages of change (4 items). Cronbach's alpha coefficients of each component were $0.75,0.64,0.84,0.85,0.71$, and the total Cronbach's alpha coefficient of this questionnaire was 0.78. Workers in the factory who promoted continuous safety activities of HCP had a better score in all dimensions than those workers in the factory who did not.

Conclusion: This questionnaire of 5 components was a well validated, predictable, and positive instrument for the HCP situation in manufacturing.

Keywords: awareness, hearing conservation, noise-induced hearing loss, preparedness 


\section{Introduction}

A hearing conservation program $(\mathrm{HCP})$ is established wherever employees are exposed to noise which is at or above $85 \mathrm{dBA}$ for an eight-hour time-weighted average. It is also promoted by the Occupational Safety and Health Administration (USA) and by the Ministry of Labor (Thailand) to protect the workers from occupational noise-induced hearing loss (NIHL). ${ }^{1,2}$ The HCP is an action program that includes at least 7 elements but the current HCP program has only (i) monitoring, (ii) audiometric testing, (iii) hearing protection devices (HPD), (iv) employee training and education, and (v) record keeping., ${ }^{1,2}$ However, an increase in the prevalence of $\mathrm{NIHL}$ was reported in various countries ${ }^{3-6}$ and in Thailand. The percentage of Thai workers who reported $\mathrm{NIHL}^{7}$ increased from $1.2 \%$ in 2000 to $4.7 \%$ in 2001. When NIHL was classified by job category, it was found that the incidence in staff personnel at Songklanagarind $\mathrm{Hospital}^{8}$ was $28.1 \%$ and in stone milling workers ${ }^{9}$ the incidence was $30.0 \%$, whereas dentistry personnel and a control group showed no significant difference. ${ }^{10}$ An effective HCP and good practices can prevent NIHL, improve employee morale and the general feeling of wellbeing, increase the quality of production, and reduce the incidence of stress-related disease. ${ }^{11}$ Hence, the authors hypothesized that awareness and preparedness should be the top safety priorities in achieving a HCP for workers in a noisy manufacturing environment.

Therefore, an awareness and preparedness HCP questionnaire was developed based on 2 theories. First, the health belief model (HBM) describes the knowledge, attitude, and readiness to act of the workers, and the factors that influence cues to action. ${ }^{12}$ Second, the stages of change model describes the confidence of personnel to achieve their behavioral change to the behavioral targets. ${ }^{13}$

In this study the questionnaire was validated using exploratory factor analysis and it was used to explain the HCP situation in 2 companies.

\section{Material and Methods}

A cross-sectional survey was conducted among 145 workers of two factories where workers were exposed to noise levels more than $85 \mathrm{dBA}$. All participants signed a consent form (EC. No.57-248-09-1). Factory 1 was a canning factory that had established some activities of the HCP in the workplace, while Factory 2 was a beverage factory that was performing all activities of the HCP. Therefore, at Factory 1, the noise level data was collected and the prevalence of $\mathrm{NIHL}$ was determined in order to conduct a focus group meeting.

\section{Validation of HCP questionnaire}

The awareness and preparedness of an HCP questionnaire ${ }^{14}$ was developed from a study by Jitjamnong. Content validity of the new version was performed by an occupational physician, psychiatric nurse, and industrial hygienist. The mean of the content validity index was calculated, where a score more than $67.0 \%$ was acceptable for each question. This new Thai version questionnaire was then translated into an English version (appendix) and back translated into a Thai version. The ability of the subjects to read and understand the questions was verified before, during, and at the end of the data collection period by observation and by asking the subjects; however, most subjects were literate.

This self-response questionnaire was conducted among 145 employees in the canning $(n=51)$ and beverage $(n=94)$ industries who voluntarily participated in this study between April 2014 and September 2015. Two parts of the original questionnaire included awareness of the HCP (21 items) which was reported on a 4-point Likert scale (Strongly agree, Agree, Disagree, and Strongly disagree), while preparedness of the HCP (4 items) was reported on a 5-point Likert scale: (i) I do it and will continue, (ii) I did it but may not continue, (iii) I think I will do it, (iv) Thought about it but never did it, and (v) Never thought about it. 
The awareness of HCP was developed based on the HBM which included perceived susceptibility (4 items), perceived severity (5 items), perceived benefits ( 2 items), perceived barriers (2 items), perceived threat ( 8 items), and the preparedness of HCP by using the stages of change model.

\section{Statistical analysis}

Descriptive statistics were used to present the data. A factor analysis was performed to clarify the components of the HCP questionnaire. An exploratory factor analysis (EFA) was then performed with the following criteria: a principal components analysis which is the default method for variable extraction, varimax rotation, and eigenvalues greater than 1.0. The factor loadings, which ranged from 0.48 to 0.91 , were reported. The statistical analyses were performed using the R program, ${ }^{15}$ version 3.2.0.

\section{Results}

\section{Demographics of study subjects}

Validation of the HCP questionnaire was performed at two factories among 145 workers who voluntarily participated in this study. There were 2 types of employees: daily and monthly workers. The mean age of the daily worker was much higher than the monthly worker. Most workers were male $(70.3 \%)$ and had graduated with a high school diploma or bachelor's degree (48.3\%). Age and educational level were significantly different between the workers and factories while gender was not (Table 1).

\section{Validity of HCP questionnaire}

The safety concerns of the workers in the HCP questionnaire included two parts: awareness and preparedness. The averages of the CVI of each questionnaire item were more than $67.0 \%$. The initial EFA of 25 items was

Table 1 Demographics of the study subjects

\begin{tabular}{|c|c|c|c|c|c|c|}
\hline \multirow{2}{*}{ Items } & \multicolumn{2}{|c|}{ Daily worker } & \multirow[b]{2}{*}{ P-value } & \multicolumn{2}{|c|}{ Monthly worker } & \multirow[b]{2}{*}{ P-value } \\
\hline & $\begin{array}{l}\text { Factory } 1 \\
(\mathrm{~N}=32)\end{array}$ & $\begin{array}{l}\text { Factory } 2 \\
(\mathrm{~N}=11)\end{array}$ & & $\begin{array}{l}\text { Factory } 1 \\
(\mathrm{~N}=19)\end{array}$ & $\begin{array}{l}\text { Factory } 2 \\
(\mathrm{~N}=83)\end{array}$ & \\
\hline \multicolumn{7}{|l|}{ Age } \\
\hline Year (meanıS.D.) & $39.6 \pm 8.2$ & $37.2 \pm 9.2$ & $<0.01^{a}$ & $39.9 \pm 9.7$ & $36.0 \pm 8.2$ & $<0.01^{a}$ \\
\hline \multicolumn{7}{|l|}{ Sex } \\
\hline Male & $13(40.6)$ & $10(90.9)$ & $0.40^{\mathrm{b}}$ & $8(42.1)$ & $71(85.5)$ & $0.04^{\mathrm{b}}$ \\
\hline Female & $19(59.4)$ & $1(0.1)$ & & $11(57.9)$ & $10(12.0)$ & \\
\hline \multicolumn{7}{|l|}{ Educational degree } \\
\hline$\leq$ Grade 12 & $8(25.0)$ & $9(81.8)$ & $<0.01^{b}$ & $0(0.0)$ & $41(49.4)$ & $<0.01^{\mathrm{b}}$ \\
\hline Diploma & $20(62.5)$ & $1(9.1)$ & & $14(73.7)$ & $35(42.2)$ & \\
\hline Bachelor & $4(12.5)$ & $1(9.1)$ & & $5(26.3)$ & $7(8.4)$ & \\
\hline
\end{tabular}

Values are presented as $\mathrm{n}(\%)$ unless indicated otherwise.

S.D.=standard deviation, 't-test, ${ }^{b}$ Fisher's exact test

Factory $1=$ canning factory, Factory $2=$ beverage factory 
used to conduct the factor analysis with the principal components factor analysis. Varimax rotation was employed for better interpretability of the factor loadings with the eigenvalues greater than 1.0. The result of the KaiserMeyer-Olkin and Bartlett's test was 0.76 ( $p$-value<0.001), and the variance was $68.5 \%$. However, there was one problem question, as expected, which was not loaded onto the expected factors. Thus, it was finally decided to drop this item and the EFA was performed again. Finally, the dimensions of awareness of HCP were revised from the dimension of "perceived susceptibility (4 items) and perceived severity (5 items)" to the dimension of "risk acceptance (8 items)", the dimension of "perceived barriers" increased from 2 to 3 items, the dimension of "perceived benefits was increased from 2 to 4 items and the dimension of "perceived threat of a problem to themselves and their employer" was decreased from 8 to 4 items in the dimension of "self-efficacy". There was one dimension of preparedness of HCP which was "stage of change". Cronbach's alpha coefficients of the components were $0.75,0.64,0.84,0.85$, and 0.71 , respectively, while the Cronbach's alpha coefficient of this questionnaire was 0.78 (Table 2).

Table 2 Dimensions and factor loadings of the awareness and preparedness questionnaire of hearing conservation program

\begin{tabular}{|c|c|c|}
\hline Item & $\begin{array}{l}\text { Dimension: risk acceptance } \\
\text { Alpha }=0.75\end{array}$ & Factor loading \\
\hline 1 & $\begin{array}{l}\text { Working in a workplace with noise above } 85 \mathrm{dBA} \text { over } 8 \text { hours every day for } 1 \text { year is a potential risk of } \\
\text { hearing loss. }\end{array}$ & 0.56 \\
\hline 2 & You are exposed to noise above the standard levels in your workplace. & 0.47 \\
\hline 3 & Your jobs put you at risk of hearing loss. & 0.57 \\
\hline 4 & Noise-induced hearing loss has a sudden onset. & 0.51 \\
\hline 5 & Working in a workplace with noise above the standard levels is a potential risk for an accident. & 0.51 \\
\hline 6 & Habitually working in a noisy workplace leads to annoyance and irritability. & 0.51 \\
\hline 7 & Noise-induced hearing loss can be permanent. & 0.53 \\
\hline \multirow[t]{3}{*}{8} & Noise-induced hearing loss cannot be cured. & 0.50 \\
\hline & Dimension: perceived barriers & Cooton londin \\
\hline & Alpha $=0.64$ & ractor loading \\
\hline 9 & Noise-induced hearing loss is neither severe nor something to fear. & 0.49 \\
\hline 10 & Wearing hearing protectors is a waste of time. & 0.79 \\
\hline \multirow[t]{3}{*}{11} & Wearing hearing protectors while working is inconvenient. & 0.69 \\
\hline & Dimension: perceived benefits & \\
\hline & Alpha $=0.84$ & Factor loading \\
\hline 12 & Hearing protectors, including ear plugs and ear muffs can help prevent noise-induced hearing loss. & 0.60 \\
\hline 13 & A hearing conservation program can reduce noise hazards for workers in a noisy workplace. & 0.58 \\
\hline 14 & $\begin{array}{l}\text { The employer's empowerment on noise prevention and control program can increase the worker's recognition } \\
\text { of noise hazards. }\end{array}$ & 0.57 \\
\hline 15 & $\begin{array}{l}\text { The employer's empowerment on noise prevention and control program will reduce the incidence of noise- } \\
\text { induced hearing loss. }\end{array}$ & 0.86 \\
\hline 16 & If leader is a role model for noise prevention and control, the worker's awareness will be increased. & 0.68 \\
\hline
\end{tabular}


Table 2 (continued)

\begin{tabular}{|c|c|c|}
\hline Item & $\begin{array}{l}\text { Dimension: role model } \\
\text { Alpha }=0.85\end{array}$ & Factor loading \\
\hline 17 & You have confidence to comply with the hearing conservation program policies. & $0.39^{*}$ \\
\hline 18 & You are confident that you can participate in all activities held by the hearing conservation program. & 0.48 \\
\hline 19 & You are confident you can be a role model for colleagues in wearing hearing protectors. & 0.91 \\
\hline \multirow[t]{2}{*}{20} & $\begin{array}{l}\text { You are confident you can be a role model for colleagues in compliance with the hearing conservation } \\
\text { program policy. }\end{array}$ & 0.90 \\
\hline & $\begin{array}{l}\text { Dimension: stage of change } \\
\text { Alpha }=0.71\end{array}$ & Factor loading \\
\hline 21 & Do you want to know the health impacts and appropriate controls of noise in your workplace? & 0.66 \\
\hline 22 & $\begin{array}{l}\text { Do you want to learn of the health impacts and appropriate controls of noise in your workplace from sources } \\
\text { that include websites, books and resource persons? }\end{array}$ & 0.59 \\
\hline 23 & Have you ever controlled or prevented noise in your workplace? & 0.62 \\
\hline 24 & $\begin{array}{l}\text { Have you ever thought about being a role model for colleagues in a noise control and prevention program in } \\
\text { your workplace? }\end{array}$ & 0.61 \\
\hline
\end{tabular}

Eigenvalue $>1.0$, variance explained $=68.5 \%$

*Item no. 17 related to component of "perceived benefits" with loading factor $=0.48$

The levels of awareness of HCP were divided into 3 categories according to the Best study ${ }^{16}$ which included fair, moderate, and good while the preparedness of HCP was divided into five categories according to the stages of change model including pre-contemplate, contemplate, preparation, action, and maintenance. However, interpretation of the self-efficacy level was divided into 2 categories which included "Yes" and "No".

Changes in life style and health behavior in terms of HCP were determined and are presented in Table 3. The results showed that the workers responded positively toward the HCP. In all dimensions of awareness of the HCP, the workers were at moderate and good levels. The participants had good confidence to be a role model in conducting the HCP. Some workers at Factory 1 were at fair levels in the dimension of risk acceptance and perceived benefit while the employees at Factory 2 were not. The mean score and level of risk perception between the monthly workers at the two factories were significantly different
( $p$-value<0.05) while other dimensions were not. For the preparedness of HCP, most workers had a good stage of behavioral change. The action level was $42.7 \%$ and maintenance level was $33.8 \%$.

\section{Discussion}

According to the safety activities in manufacturing, such as training in NIHL, wearing and storage of HPDs, selection of HPD, observation of wearing a HPD by their supervisors, the perceived susceptibility and perceived severity by the workers had increased. These previous dimensions can be combined into one dimension which is consistent with Hall who suggested that the perceived threat included susceptibility and seriousness, ${ }^{17}$ while some items of "perceived threat" can be moved to other dimensions and the remaining items can be represented in the dimension of "self-efficacy". According to the selfefficacy model, it is proposed as a separate independent variable along with the traditional $\mathrm{HBM}^{12}$ 
Table 3 Levels of the awareness and preparedness of the HCP in each dimension

\begin{tabular}{|c|c|c|c|c|c|c|}
\hline \multirow{2}{*}{ Components } & \multicolumn{2}{|c|}{ Daily worker } & \multirow[b]{2}{*}{$\mathrm{P}$-value } & \multicolumn{2}{|c|}{ Monthly worker } & \multirow[b]{2}{*}{ P-value } \\
\hline & $\begin{array}{l}\text { Factory } 1 \\
(\mathrm{~N}=32)\end{array}$ & $\begin{array}{l}\text { Factory } 2 \\
(\mathrm{~N}=11)\end{array}$ & & $\begin{array}{l}\text { Factory } 1 \\
(\mathrm{~N}=19)\end{array}$ & $\begin{array}{l}\text { Factory } 2 \\
(\mathrm{~N}=83)\end{array}$ & \\
\hline Risk acceptance* & $3.2 \pm 0.5$ & $3.3 \pm 0.4$ & $0.69^{b}$ & $2.9 \pm 0.3$ & $3.2 \pm 0.4$ & $<0.01^{\mathrm{a}}$ \\
\hline Fair & 1 & 0 & & 0 & 0 & \\
\hline Moderate & 10 & 4 & $>0.05^{\mathrm{c}}$ & 14 & 34 & $0.02^{d}$ \\
\hline Good & 21 & 7 & & 5 & 49 & \\
\hline Perceived barriers* & $2.8 \pm 0.5$ & $2.9 \pm 0.4$ & $0.67^{\mathrm{a}}$ & $2.9 \pm 0.4$ & $2.9 \pm 0.4$ & $0.73^{\mathrm{a}}$ \\
\hline Fair & 3 & 0 & $0.69^{\circ}$ & 1 & 1 & $0.34^{c}$ \\
\hline Moderate & 29 & 11 & & 18 & 82 & \\
\hline Perceived benefits* & $3.4 \pm 0.5$ & $3.5 \pm 0.4$ & $0.91^{\mathrm{a}}$ & $3.6 \pm 0.5$ & $3.4 \pm 0.4$ & $0.08^{\mathrm{a}}$ \\
\hline Fair & 2 & 0 & & 0 & 0 & \\
\hline Moderate & 19 & 7 & $>0.05^{\mathrm{c}}$ & 10 & 59 & $0.58^{d}$ \\
\hline Good & 11 & 4 & & 9 & 24 & \\
\hline Role Model ${ }^{*}$ & $3.2 \pm 0.4$ & $3.3 \pm 0.5$ & $0.42^{\mathrm{a}}$ & $3.3 \pm 0.4$ & $3.3 \pm 0.4$ & $0.60^{\mathrm{a}}$ \\
\hline Yes & 32 & 11 & & 19 & 83 & \\
\hline Stage of change ${ }^{*}$ & $3.8 \pm 1.0$ & $3.8 \pm 1.1$ & $0.92^{\mathrm{a}}$ & $4.0 \pm 0.9$ & $3.8 \pm 0.9$ & $0.45^{a}$ \\
\hline Pre-contemplate & 1 & 0 & & 0 & 0 & \\
\hline Contemplate & 2 & 1 & & 1 & 4 & \\
\hline Preparation & 6 & 4 & $0.46^{\mathrm{c}}$ & 2 & 22 & $0.57^{\circ}$ \\
\hline Action & 14 & 2 & & 8 & 28 & \\
\hline Maintenance & 9 & 4 & & 8 & 28 & \\
\hline
\end{tabular}

Values are presented as $\mathrm{n}$ unless indicated otherwise.

*Mean \pm standard deviation

a'Wilcoxon rank sum test, 'bt-test, 'Fisher's exact test, 'Pearson's chi-squared test

Perceived barriers were the negative consequences of outcomes or effects of those activities while benefits were the effectiveness or advantages of the program. ${ }^{17}$ Therefore, one perceived benefit by the workers of the HCP was how to protect themselves from NIHL which came from the education program or safety activities such as wearing and using the right type of HPD. The workers then had more knowledge and were confident or had selfefficacy to be a role model. ${ }^{18}$ Hence, the workers had decreased barriers and they perceived increased benefits which in this situation had the effect of multiple health behavior changes. ${ }^{19}$ These results were contrary to a study by Brown which found that undergraduate students had a significantly positive association between benefits, barriers, and self-efficacy. ${ }^{20}$ However, the physical activities (weekly kilocalories) of undergraduate students were negatively associated with perceived barriers $(r=-0.11)$, while a perceived benefit had a significantly positive association 
$(r=0.2)$. In addition, Mahoney et al. ${ }^{21}$ found that the HBM was best at identifying sporadic condom users while the selfefficacy model was relevant to consistent condom use.

Well-motivated and appropriately qualified personnel were significant to the success. The greater the employer's empowerment and motivation, greater were the worker benefits and worker confidence to participate, ${ }^{22}$ especially in the HCP. These results can be explained by a good working environment that promotes the empowerment of employees which is more likely to "gain" their trust. ${ }^{23}$ In addition, Nayak et al. ${ }^{24}$ found that the willingness of the participants to do yoga depended on their perception of benefits and barriers. Therefore, the workers had good risk judgment or decision making in their capacities which was related to sociopsychological theory of decision making to individual health related behaviors. ${ }^{25}$ The workers were then confident that they could be role models for colleagues in the wearing of a HPD. These results were consistent with the Ko et al. ${ }^{26}$ study which found a lower level of self-efficacy among heroin users who received methadone maintenance treatment and Han et al. ${ }^{27}$ who pointed out that the lower effectiveness of HPD included bad attitude, poor risk perception, and low self-efficacy in the use of HPDs. For the stage of change, Hong et al. ${ }^{28}$ found an inconsistency with this study where the participants in the action/ maintenance stage demonstrated significantly greater benefits, self-efficacy, and barriers.

For implementation of this questionnaire, Factory 2 established the HCP in 2011 while Factory 1 had already implemented the HCP several years earlier with some HCP activities, HCP policy, and annual audiometry test. However, Factory 2 performed and promoted continuous safety activities of HCP while Factory 1 had not. These supported the findings that the worker's risk acceptance and perceived benefit of Factory 1 were lower than the workers at Factory 2. According to the focus group discussion, there were some workers at Factory 1 who had been using cotton instead of a HPD and the new employees had no training in a HCP or on the wearing of HPDs. These results were consistent with the results of wearing HPDs. We found that some workers had inserted the ear plugs in the wrong way. The score of role model and stage of change of workers were consistent. This implied that the awareness and preparedness of most workers were at quite good levels. Therefore, changes in their behavior during the next 6 months should be possible. ${ }^{13}$

These results implied that this questionnaire could indicate that worker perceptions of the HCP at Factory 2 had better levels than those workers at Factory 1.

\section{Conclusion}

The worker safety concerns of the HCP questionnaire included the dimensions of risk acceptance, perceived barriers, perceived benefits, self-efficacy, and the stages of change. The validation of this questionnaire was good, predictable, and positive toward the HCP situation in these companies.

\section{Acknowledgement}

This research was supported by a grant from the Faculty of Medicine, Prince of Songkla University, Thailand (No. 57-248-09-1).

\section{References}

1. Occupational Safety and Health Administration, US Department of Labor. Hearing conservation (OSHA 30742002). Washington: OSHA; 2002.

2. Ministry of Labor, Thailand. Rules and procedures for preparation of a hearing conservation program in the workplace. Royal Gazette, 20 May B.E. 2553.

3. Miyakita T, Ueda A. Estimates of worker with noise-induced hearing loss and population at risk. J Sound Vib 1997;205:441-9.

4. Musiba Z. The prevalence of noise-induced hearing loss among Tanzanian miners. Occup Med 2015. Doi: 10.1093/occmed/ kqv046. 
5. Nandi SS, Dhatrak SV. Occupational noise-induced hearing loss in India. Indian J Occup Environ Med 2008;12:53-6.

6. Osibogun A, Igweza IA, Adeniran LO. Noise-induced hearing loss among textile workers in Lagos metropolis. Niger Postdrad Med J 2000;7:104-11.

7. Tantranont K, Srisuphan W, Kaewthummanukul T, Suthakorn W, Jormsri P, Salazar M. Factors affecting Thai workers' use of hearing protection. AAOHN 2009;57:455-63.

8. Pholchan T, Peeravud S, Chayarpham S, Tuntiseranee P. Noiseinduced hearing loss and its determinants among workers in food supply, central supply and maintenance departments at Songklanagarind Hospital. Songkla Med J 2004;22:27-36.

9. Pethprapan R, Khaimook W, Choosong T. Evaluation of noise levels and noise-induced hearing loss of workers at stone milling factory. J Safety Health 2004;8:13-23.

10. Khaimook W, Suksamae P, Choosong T, Chayarpham S, Tantisarasart R. The prevalence of niose-induced occupational hearing loss in dentistry personnel. Workplace Health Saf 2014;62:357-60.

11. Berry C. A guide to developing and maintaining an effective hearing conservation program. Washington: Occupational Safety and Health Division; 2012.

12. Rosenstock IM, Strecher VJ, Becker MH. Social learning theory and health belief model. Health Educ Q 1988;15:175-83.

13. McKenzie JF, Neiger BL, Thackeray R. Planning, implementing, and evaluating health promotion programs: a primer. $5^{\text {th }}$ ed. California: Pearson Benjamin Cummings; 2009.

14. Jitjamnong A. An awareness and readiness to hearing conservation program in industrial technical department of vocational collage, Songkhla Province [Dissertation]. Songkhla: Prince of Songkla University; 2010.

15. R-project.org. The $\mathrm{R}$ project for statistical computing [homepage on the Internet]. Vienna: R Foundation for Statistical Computing [cited 2015 Aug 10]. Available form: http://www. R-project.org/

16. Best JW. Research in education. $3^{\text {rd }}$ ed. Englewood Cliffs: Prentice Hall; 1977.
17. Hall KS. The health belief model can guide modern contraceptive behavior research and practice. J Midwifery Woman Health 2012;57:74-81.

18. Dell SM, Holmes AE. The effect of a hearing conservation program on adolescents' attitudes towards noise. Noise Health 2012;14:39-44.

19. Prochaska JJ, Spring B, Nigg CR. Multiple health behavior change research: an introduction and overview. Prev Mede 2008;46:181-8.

20. Brown SA. Measuring perceived benefits and perceived barriers for physical activity. Am J Health Behav 2005; 29:10716.

21. Mahoney CA, Thombs DL, Ford OL. Health belief and selfefficacy models: their utility in explaining college student condom use. AIDS Educ Prev 1995;7:32-49.

22. Papathanasiou IV, Fradelos EC, Kleisiaris CF, Tsaras K, Kalota MA, Kourkouta L. Motivation, leadership, empowerment and confidence: their relation with nurses' burnout. Mater Sociomed 2014;26:405-10.

23. Laschinger $H$, Sabiston JA. Staff nurse empowerment and workplace behaviors. Can Nurse 2000;96:18-22.

24. Nayak HD, Patel NK, Wood R, Dufault V, Guidotti N. A study to identify the benefits, barriers, and cues to participating in a yoga program among community dwelling older adults. Yoga Physical Therapy 2014. Doi: 10.4172/2157-7595.1000178.

25. Harrison JA, Mullem PD, Greem LW. A meta-analysis of studies of the health belief model with adults. Health Educ Res 1992;7:107-16.

26. Ko NY, Wang PW, WU HC, Yen CN, Hsu ST, Yeh YC, et al. Self-efficacy and HIV risk behaviors among heroin users in Taiwan. JSAD 2012;73:469-76.

27. Han LM, Haron Z, Jahya Z, Darus N, Abdul Hamid MF. A prototyping model of intelligent hearing protection device. Jurnal Teknologi (Sciences \& Engineering) 2015;74:1-6.

28. Hong O, Chin DL, Kerr MJ, Ronis DL. Stages of change in hearing-protection behavior, cognition, and hearing status. Am J Health Behav 2012;36:811-22. 